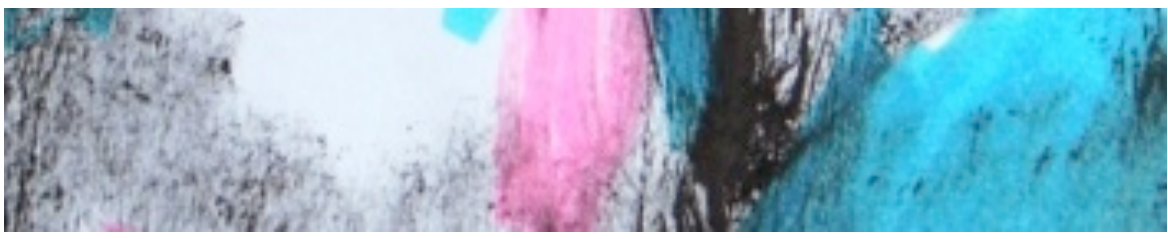

\title{
Abuso de la metáfora y laxitud conceptual en Comunicación
}

\section{Metaphor abuse and conceptual laxity in Communication}

\author{
Juan Ramón Muñoz-Torres ${ }^{(*)}$ \\ Universidad Complutense de Madrid - España \\ torres@,ccinf.ucm.es
}

\section{Resumen \\ En el campo de la Comunicación, la metá- fora abunda por doquier. Entre las más importantes, la metáfora tecnológica im- plícita en la Teoría Matemática de la Comunicación ha sido una de las más omnipresentes e influyentes durante las últimas décadas, porque las premisas y conceptos subyacentes en ella han ahorma- do la reflexión académica sobre la comuni- cación humana. Este texto trata de argu- mentar que las principales deficiencias en la definición del campo, en gran medida debidas al formalismo y la laxitud concep- tual, derivan del abuso de la metáfora.}

Palabras clave: comunicación, metá-

\begin{abstract}
In the field of Communication, metaphor abounds everywhere. Among the most important ones, the technological metaphor embedded in the Mathematical Theory of Communication has been most pervasive and influential during the last decades, because the premises and concepts underlying in it have shaped the academic reflection upon human communication. This paper attempts to argue that the main shortcomings in the definition of the field, largely due to formalism and conceptual laxity, stem from the abuse of the metaphor.
\end{abstract}

Keywords: communication, metaphor, 
«Abuso de la metáfora y laxitud conceptual en comunicación»

fora, laxitud conceptual, pancomunica- conceptual laxity, pancommunication, cionismo, formalismo. formalism 
Half the wrong conclusions at which mankind arrives are reached by the abuse of metaphors.

Lord Palmerston

\section{INTRODUCCIÓN}

El ser humano no sabe expresarse sin el recurso continuado a la metáfora (esta misma afirmación así lo muestra). Basta una mínima reflexión sobre nuestra experiencia inmediata, para percatarse de que el uso del lenguaje figurado está siempre omnipresente, de una u otra manera, bien sea en el ámbito de la vida cotidiana, bien en el del discurso académico o científico-técnico. Más aún, nuestro mismo sistema conceptual es -como han mostrado convincentemente Lakoff y Johnson (1980a: 453-486)—, en gran medida, metafórico.

Para entender plenamente el alcance y trascendencia de las afirmaciones anteriores, urge definir, aunque sea sucintamente, el concepto de metáfora. A tal efecto, conviene empezar por precisar que metafórico no significa — como mucha gente piensa- meramente "ornamental" o "estilístico".

Lo metafórico no es sola, ni principalmente, una característica accesoria del uso de las palabras. Por su misma naturaleza, la metáfora tiene más que ver con el pensamiento que con la forma lingüística mediante la cual este se expresa. La razón es clara: la metáfora es, en esencia, una relación conceptual por la que entendemos y expresamos un tipo de cosas en términos de otras, a partir de la analogía que hay entre ambas. Tal como la define el Diccionario de la Real Academia, la metáfora supone transmutar el sentido literal de una o varias palabras en otro, figurado, "con el fin de sugerir una comparación (con otro objeto o concepto) y facilitar su comprensión” (DRAE, 22 ed). Así, por ejemplo, podemos afirmar, de manera metafórica, con Shakespeare, que el mundo es un teatro en el que hombres y mujeres son los actores que entran y salen de escena; o también que el átomo es un sistema solar en miniatura; o que la vida es un viaje; o que tal descubrimiento médico aporta un rayo de esperanza; etc., etc.

Así pues, la metáfora es un tipo de relación conceptual entre realidades análogas, que permite comprenderlas y expresarlas mejor. El acento debe ponerse, pues, en la analogía, es decir, en la relación implícita de se-

Mediaciones Sociales, № 11, II semestre 2012, pp. 3-26. ISSN electrónico: 1989-0494. http://dx.doi.org/10.5209/rev_MESO.2012.v11.41267 
mejanza entre cosas diferentes. Solo en la medida en que conseguimos establecer una adecuada analogía entre dos seres distintos (por ejemplo, entre el mundo y el teatro), logramos que el juego de la metáfora funcione de manera eficaz. Y, al contrario, si la analogía no está bien concebida, la metáfora se vuelve vacía, incomprensible o induce a confusión. Vemos, de nuevo, que el uso metafórico del lenguaje depende, ante todo, del pensamiento y de su capacidad de relación, más que de la forma concreta del lenguaje figurado, del tropo como artificio lingüístico. En definitiva, es posible y provechoso desviarse del sentido literal de las palabras y cambiarlo por otro figurado, más iluminador, pero a condición de que tenga fundamento la analogía entre los conceptos expresados (sentido figurado) y los sustituidos (sentido literal).

Tomemos un ejemplo para ilustrar mejor el punto anterior. Es obvio que el tiempo y el dinero son realidades completamente diferentes. Pero no lo es menos que ambas realidades comparten rasgos semejantes, que permiten establecer analogías entre ellas y, por tanto, juegos metafóricos. Básicamente, las semejanzas entre el tiempo y el dinero radican en que ambos son bienes escasos y, por tanto, valiosos. Además, ambos son medios necesarios, en mayor o menor medida, para conseguir nuestros propósitos (de donde deriva también su carácter valioso). Por consiguiente, pese a las diferencias evidentes entre tiempo y dinero, podemos hacer afirmaciones nada descabelladas y tan frecuentes como las que siguen: "el tiempo es oro"; "he invertido mucho tiempo en la tarea"; "no tengo tiempo para ella"; "le ha costado mucho tiempo lograrlo"; "he perdido mucho tiempo en la espera”; “¿te queda tiempo para eso?”; "ha reservado un tiempo para estar con sus hijos"; etc.

Hasta tal punto es lógico y razonable recurrir al lenguaje metafórico para expresarnos mejor que, incorporadas como están a nuestra percepción de la realidad, las metáforas nos pasan inadvertidas habitualmente. Pensemos, por ejemplo, en expresiones metafóricas tan cotidianas como las siguientes: "la explosión de la burbuja inmobiliaria"; "la crisis del ladrillo"; "la lucha contra el cáncer"; "bombardear a preguntas"; "el recalentamiento de la economía”; "dar un balón de oxígeno”; "arrimar el ascua a su sardina”; "contener la inflación (etimológicamente: "hinchazón”) de los precios”; "meter un gol al gobierno"; "conceder carta de naturaleza"; "hundirse en la miseria”; "plantar cara al fraude"; etc. 
El uso compartido y reiterado de ciertas metáforas las convierte, con el paso del tiempo, en un recurso cómodo y fácil, del cual es, a veces, difícil prescindir (p. ej.: "la elasticidad de la oferta y la demanda" o "la expresión proteica de los genes”). Cuando esto ocurre es porque la metáfora ha llegado a convertirse en un lugar común recurrente, en el cual el sentido figurado está tan consolidado que "echa raíces" en la mentalidad colectiva. Dicho de otra manera, la metáfora no es solo efecto del pensamiento, sino que - más importante aún- lo configura y ahorma. La prueba más clara de ello es el esfuerzo que comporta pensar la realidad sin recurrir a las figuras de pensamiento (pensemos, por ejemplo, en lo arduo que resulta explicar sin metáforas determinados fenómenos de la física, de la química, de la medicina, de la economía, etc.). Así pues, no solo pensamos y nos expresamos a través de metáforas, sino que, al hacerlo, la propia metáfora inevitablemente acaba por constreñir y tamizar nuestra capacidad de conocer y de reflexionar (por ejemplo, es difícil concebir un debate académico o político en términos que no sean de lucha o confrontación) ${ }^{1}$.

Apuntada la importancia crucial de la metáfora en relación con el conocimiento, llega el momento de decir que la metáfora ha desempeñado -y lo sigue haciendo - un papel decisivo en la reflexión académica sobre la comunicación humana en general. En efecto, son muchas las metáforas que se han utilizado y se siguen utilizando en este ámbito y, en particular, en el más reducido de la comunicación mediática. Sin pretensión de exhaustividad, recordemos algunas de las muchas formas bajo las cuales los medios se han presentado a sí mismos a lo largo del tiempo. Entre ellas, abundan las metáforas de la intermediación (los medios como mensajeros, testigos cualificados o notarios de la actualidad); las de carácter especular (los medios como espejo que refleja objetivamente la realidad o como ventana al mundo); las relativas a la iluminación y la orientación (los medios como faro, linterna, brújula, atalaya, guía, etc.); las que los presentan como "enmarcadores" o "seleccionadores" de la realidad (teoría del framing y de la agenda-setting); las referidas a su labor de control y contrapoder (los medios como árbitros imparciales, como jueces paralelos, como perros guardianes, como defensores de la libertad, etc.).

1 En las obras antes citadas, Lakoff y Johnson ofrecen atinados ejemplos de cómo el uso repetido de ciertas metáforas acaba por condicionar nuestra manera de pensar los asuntos de la vida cotidiana. Aunque no comparto la radical universalidad de la conceptual metaphor theory, desarrollada por estos autores, estimo que tienen mucha razón en una parte sustancial de sus planteamientos centrales. Para el ejemplo, cfr. Lakoff y Johnson, 1980a: 454-455.

Mediaciones Sociales, № 11, II semestre 2012, pp. 3-26. ISSN electrónico: 1989-0494. http://dx.doi.org/10.5209/rev_MESO.2012.v11.41267 
Todas estas metáforas - y otras muchas que se podrían añadir- están cargadas de conceptos y juicios subyacentes de todo tipo (filosóficos, políticos, económicos, etc.), que condicionan, para bien o para mal, nuestra concepción de los medios y de la labor que realizan. Por eso, creo que su análisis, muy poco frecuente, puede resultar valioso y enriquecedor. Como una mínima contribución a él, el presente estudio se propone ofrecer unas consideraciones sucintas - y ojalá que enjundiosas- sobre una de las metáforas $^{2}$ que ha inspirado el alumbramiento y desarrollo de otras muchas posteriores: la metáfora tecnológica, que presenta la comunicación humana en general, y los medios en particular, como un proceso similar al de las conexiones cibernéticas o telemáticas. En las páginas que siguen, intentaré mostrar: a) hasta qué punto y de qué manera ha sido influyente la metáfora tecnológica; y b) en qué medida su éxito ha tenido efectos negativos en forma de formalismo y laxitud conceptual, a la hora de establecer los límites del campo de la comunicación.

\section{EL ORIGEN DE LA METÁFORA EN LOS ESTUDIOS SOBRE COMUNI- CACIÓN}

Pienso que no es aventurado sostener que, en los inicios de los Communication Studies en Estados Unidos, todo el esfuerzo creador de los padres fundadores ${ }^{3}$ del campo estuvo inspirado y marcado, en buena medida, por el uso de la metáfora. Más concretamente, por la metáfora creada por la teoría matemática de la comunicación, de Claude Elwood Shannon. Como sabemos, a partir de 1948, esta teoría fue el gran hito miliar que marcó el principio del camino de la reflexión posterior sobre la naturaleza de la comunicación, instaurando así un paradigma que ha perdurado durante décadas hasta nuestros días.

2 Debo advertir que no siempre usaré el término "metáfora" en el sentido preciso antes apuntado; en ocasiones -fácilmente distinguibles por el contexto-, emplearé esta palabra como sustantivo genérico que engloba distintas formas del lenguaje figurado (por ejemplo, metonimia, personificación, sinécdoque). Para las diferencias entre metáfora y metonimia, cfr. el texto ya clásico de Roman Jakobson (Jakobson y Halle, 1956).

3 Me refiero, principalmente, a Paul F. Lazarsfeld, Harold Lasswell, Carl Hovland y a Wilbur Schramm.

Mediaciones Sociales, № 11, II semestre 2012, pp. 3-26. ISSN electrónico: 1989-0494. http://dx.doi.org/10.5209/rev_MESO.2012.v11.41267 
Conviene recordar que Shannon no era un teórico de la comunicación, sino un matemático e ingeniero electrónico, que trabajaba para la American Bell Telephone Company. Su trabajo no estaba, pues, encaminado a entender el fenómeno de la comunicación humana — ni en el plano personal, ni en el colectivo-, sino a mejorar la eficacia de las líneas telefónicas de su época ${ }^{4}$. Ya en su artículo seminal de 1948 (Shannon, 1948), pomposamente titulado "una teoría matemática de la comunicación”, base de la influyente teoría posterior, su autor dejaba claro que lo que se proponía era determinar formalmente cuáles eran las condiciones óptimas para la transmisión electrónica de señales, con independencia de cuál pudiera ser el contenido de los mensajes transmitidos. Se trataba, pues, de un estudio formal, de carácter cuantitativo, sobre el transporte de señales electromagnéticas, en el que -en sus propias palabras - los "aspectos semánticos de la comunicación son irrelevantes para el problema de ingeniería” (Shannon, 1948: 3796).

Sin entrar ahora a valorar las aportaciones de la llamada "teoría matemática de la comunicación”, no se puede obviar que la obra de Shannon tuvo grandes puntos fuertes, que explican en parte su enorme éxito: su esquema básico era sencillo y claro; tenía un carácter formal, que la hacía universalmente válida; y, además, permitía resultados cuantificables. Por si esto fuera poco, unida al descubrimiento coetáneo del transistor, dio origen al embrión de lo que, con el tiempo, serían la informática y las telecomunicaciones, sin los cuales no existiría el mundo tal como lo conocemos en el presente. No obstante, en lo que respecta al tema que nos ocupa, lo destacable aquí es que la teoría matemática estableció un paradigma conceptual metafórico, que ha inspirado, para bien y para mal, la reflexión posterior sobre el fenómeno de la comunicación.

En efecto, los elementos básicos de esa teoría, universalmente conocidos (emisor, codificador, mensaje, decodificador, receptor, canal, etc.), conformaron una forma metafórica de entender la comunicación humana en

4 Una excelente exposición de las circunstancias históricas y del contexto intelectual en que nació la teoría matemática, así como de sus fundamentos teóricos, en Gleick, 2011 (en especial, caps. 6-8).

5 En mi opinión, el artículo citado debería haberse titulado de una forma mucho más precisa y modesta; por ejemplo, de un modo parecido a: "estudio de las condiciones formales óptimas para la transmisión de señales electromagnéticas". Este texto fue la base del célebre libro posterior, publicado en coautoría con Warren Weaver, que hizo de divulgador de la teoría de Shannon (Shannon y Weaver, 1949).

6 La traducción es mía y también lo será en adelante, salvo que se indique lo contrario.

Mediaciones Sociales, № 11, II semestre 2012, pp. 3-26. ISSN electrónico: 1989-0494. http://dx.doi.org/10.5209/rev_MESO.2012.v11.41267 
general ${ }^{7}$, a partir de una comparación implícita entre esta y la interacción entre máquinas que transportan señales electrónicas. Con ello, la teoría matemática adquirió un valor de paradigma o modelo, principalmente por su alta capacidad divulgativa, a partir de un esquema básico, claro y asequible. Buena prueba de este valor paradigmático se manifiesta en que algunos de sus conceptos más elementales, junto con sus presupuestos subyacentes, fueron recogidos, desarrollados y reelaborados por numerosos teóricos de la comunicación, que alumbraron diversos "modelos de la

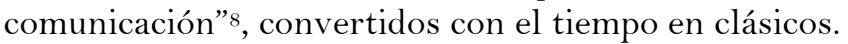

Ahora bien, como he apuntado al principio, no todo uso de la metáfora es necesariamente enriquecedor y fecundo. No me refiero ahora a aquellos casos en los que, por una analogía mal elegida, la metáfora "no funciona" o lo hace de manera poco eficaz (por ejemplo, "deslumbrando mucho" e "iluminando poco”). Pienso más bien en aquellos casos en los cuales aspectos diferenciales de las realidades comparadas quedan completamente "en sombra”, justamente porque la luz de la metáfora recae con demasiada fuerza sobre los aspectos semejantes ${ }^{9}$. Esto es lo que, en mi opinión, sucede con la metáfora tecnológica de la comunicación, implícita en la teoría matemática, como veremos enseguida.

En efecto, en los conceptos y presupuestos de la teoría matemática y, sobre todo, en sus desarrollos posteriores, hay una "reducción metonímica”, en la que se toma el todo de la comunicación humana por una de sus partes, la transmisión de signos mediante señales electrónicas. Así, la comunicación queda concebida, reductivamente, como un proceso formal y mecánico de envío y reproducción a distancia de mensajes, es decir, como la mera transmisión o intercambio de información $n^{\prime 0}$. Igualmente, el contenido de

7 Su influjo alcanzó a campos muy diversos. Baste recordar, a modo de ejemplo, cómo Jakobson se inspiró en la teoría matemática para desarrollar su célebre teoría de las funciones lingüísticas (Jakobson, 1960).

8 Pienso, por ejemplo, en los modelos de Schramm (1954), Westley-MacLean (1957), Berlo (1960), McCroskey (1968).

9 Al recurrir al uso de la metáfora, es extremadamente difícil alcanzar un juicio equilibrado y justo en la confrontación de los aspectos semejantes y los diferentes que existen entre las realidades comparadas metafóricamente. En efecto, al fijar la atención en lo semejante, con frecuencia se corre el riesgo de preterir o negar lo diferente. Igualmente, si se pone excesivo énfasis en lo diferente, las semejanzas tienden a desdibujarse.

${ }^{10}$ De hecho, el propio Shannon llegó a simplificar burdamente la cuestión en los siguientes términos: "el problema fundamental de la comunicación radica en reproducir exacta o aproxi- 
la comunicación, es decir, el sentido que emisor y destinatario comparten, queda cosificado y reducido al concepto de información o de mensaje, que, a su vez, se reduce a un código binario, transmitido mediante impulsos electromagnéticos. Algo similar se podría afirmar de otros conceptos como los de ruido, canal o retroalimentación.

En el fondo, lo que se presupone es que la comunicación humana — tanto individual como colectiva- no es más que un mero intercambio de mensajes, de carácter procesual y mecanicista. Según la metáfora implícita, el hablante es el emisor, que pretende transmitir una idea (contenido mental), la cual vierte en un contenedor lingüístico (codificación del mensaje) y envía mediante signos (señales electromagnéticas), a través de un canal técnico, a otro interlocutor (destinatario). Este revierte el proceso (decodificación, interpretación de la idea) y puede, a su vez, iniciarlo en la dirección contraria (retroalimentación).

Es obvio que, en todo acto de comunicación humana, hay necesariamente dos términos: emisor y destinatario. No lo es menos que las ideas necesitan del intercambio de signos lingüísticos para "pasar" de la mente del emisor a la del destinatario. También es innegable que en la plasmación lingüística del sentido puede haber errores de "codificación” (expresión incorrecta) o de "decodificación” (interpretación incorrecta). Y, sin embargo, siendo todo esto verdad, los conceptos mencionados solo explican una parte menor de la realidad de la comunicación humana, que es infinitamente más compleja que el mero intercambio de mensajes cerrados y cosificados entre máquinas (sean estas los rudimentarios sistemas de telefonía de la década de los 50 o los potentes sistemas informáticos de hoy en día).

Con las afirmaciones anteriores no estoy negando, por supuesto, la existencia de aspectos materiales indispensables para que se dé el acto comunicativo (ni tampoco, claro, el legítimo derecho a estudiarlos). Por ejemplo, la capacidad de emitir ciertos sonidos mediante la voz es imprescindible para la comunicación oral y objeto de estudio de la fonética. Ahora bien, comunicarse oralmente implica mucho más que poder emitir ciertos sonidos. Por eso, la comunicación humana nunca debería quedar reducida a

madamente en un punto determinado un mensaje seleccionado en otro punto" (Shannon, 1948: 379).

Mediaciones Sociales, № 11, II semestre 2012, pp. 3-26. ISSN electrónico: 1989-0494. http://dx.doi.org/10.5209/rev_MESO.2012.v11.41267 
este aspecto material. Siguiendo con la analogía, es igualmente obvio que la comunicación requiere ciertas condiciones materiales relativas a la construcción e intercambio de mensajes, al uso de un canal, etc. El estudio de tales aspectos es, sin duda, legítimo y relevante. Lo que, en cambio, me parece rechazable es la reducción que se ha hecho, históricamente, de la comunicación, al concebirla esencial y primariamente como un mero transporte material de mensajes.

Dicho con otras palabras: el problema de la metáfora comunicativa subyacente en la teoría matemática y en sus derivaciones posteriores es que toda ella está basada, como ya he apuntado, en una analogía deficientemente establecida: la que compara implícitamente la "interacción” entre máquinas con la relación comunicativa entre personas. Como acabamos de ver, es innegable que entre ambos tipos de relación existen claras semejanzas, pero no es menos evidente que también hay grandes diferencias, mayores - a mi juicio - que las primeras (por ejemplo, el carácter inteligente, libre y sujeto a emociones del ser humano).

En definitiva, en la concepción humanista del concepto de comunicación que sostengo, los aspectos materiales del acto comunicativo son condiciones necesarias que lo hacen posible. Ahora bien, su carácter necesario no los convierte en suficientes. Por eso, a mi entender, solamente a partir de los aspectos materiales, no es posible dar razón de la dimensión intelectual, volitiva y emocional (espiritual, en definitiva) de la comunicación humana, que nunca quedará satisfactoriamente explicada como mero transporte de mensajes.

A continuación, intentaré mostrar brevemente que, en el caso que nos ocupa, el recurso a la metáfora ha sido, en conjunto, abusivo (porque se han excedido ampliamente los límites razonables de la analogía) y, a largo plazo, contraproducente. La razón es clara: puesto todo el foco de luz en las semejanzas, se han ensombrecido o ignorado las diferencias; es decir, las otras facetas de la comunicación humana que desbordan ampliamente el marco conceptual de la interacción entre máquinas (por ejemplo, los aspectos semánticos y pragmáticos - ilocutivos y perlocutivos- de la comunicación, en los que intervienen múltiples factores: emotivos, psicológicos, sociológicos, espacio-temporales, etc.). Esto ha supuesto un empobrecimiento notable del concepto de comunicación humana y ha abierto la puer-

Mediaciones Sociales, № 11, II semestre 2012, pp. 3-26. ISSN electrónico: 1989-0494. http://dx.doi.org/10.5209/rev_MESO.2012.v11.41267 
ta a la arbitrariedad en la definición de los límites de su estudio, a través del formalismo y la laxitud conceptual, como veremos a continuación.

\section{AlCANCE Y EFECTOS DEL USO DE LA METÁFORA COMUNICATI- $V A$ ORIGINARIA}

Cuando Shannon afirma, con toda razón, que el contenido semántico de la comunicación es irrelevante para sus propósitos, establece —quizá sin ser consciente de ello- el rasgo fundamental que permea todo su entramado conceptual y, por supuesto, la metáfora subyacente en él: el formalismo. En efecto, al concebir esencialmente la comunicación como un mero intercambio de "mensajes", con independencia de su significado, pone el acento en el continente, es decir, en la forma externa de lo comunicado, en detrimento de su contenido. Así, la influencia de esta metáfora tecnológica, que podríamos llamar la metáfora comunicativa originaria, ha hecho que la reflexión posterior sobre la comunicación humana, se haya centrado igualmente en rasgos formales accidentales: básicamente, en su carácter relacional y procesual y en su carácter semiótico. En cambio, lo que más esencialmente define, a mi entender, la naturaleza de la comunicación ha quedado, con frecuencia, ensombrecido u oculto: por una parte, su carácter de acción humana, y como tal, inteligente y libre; y por otra, aquello que emisor y receptor comparten: el significado semántico y el sentido pragmático del contenido compartido.

Llegados a este punto, conviene plantearse inmediatamente la siguiente pregunta: cuál ha sido el alcance y el grado de influencia que el sistema conceptual metafórico subyacente en la teoría matemática ha tenido, históricamente, en el desarrollo de los estudios sobre comunicación. Dadas la complejidad del tema y las limitaciones de este estudio, habrá que dejar para otro lugar una respuesta más completa, detallada y matizada a estas preguntas. Aquí tendremos, pues, que conformarnos solo con abocetar esquemáticamente dos cuestiones estrechamente relacionadas, que considero consecuencia directa de la "forma mental" implícita en la metáfora comunicativa originaria: el formalismo inherente al campo de investigación en comunicación y la falta de rigor que habitualmente va unida a él.

En primer lugar, el formalismo de la metáfora tecnológica ha dejado su impronta, de diversas maneras, en muchas de las cuestiones medulares de

Mediaciones Sociales, № 11, II semestre 2012, pp. 3-26. ISSN electrónico: 1989-0494. http://dx.doi.org/10.5209/rev_MESO.2012.v11.41267 
la investigación en comunicación. Sin pretensión de exhaustividad, a continuación enumeraré algunas de esas cuestiones en las que, a mi parecer, tal influencia es más patente:

1. Indefinición conceptual sobre la naturaleza propia de la acción comunicativa: la pregunta clave por el qué de la comunicación suele quedar ignorada o reemplazada por la pregunta por el cómo. En consecuencia, las descripciones y los esquemas formales sustituyen habitualmente a los intentos de definición y de reflexión conceptual (pensemos, por ejemplo, en la acusada tendencia a la construcción de "modelos", antes aludida).

2. Para definir algo como comunicación o comunicativo, se toma como condición suficiente lo que solo es condición necesaria: el carácter relacional. Basta con establecer casi cualquier tipo de relación entre dos entes, o incluso de un ente consigo mismo, para considerar que hay comunicación; por ejemplo: las relaciones entre personas, animales o máquinas; así, se dice que los planetas comunican, como también lo hacen las abejas, los medios, las empresas, los gobiernos, los países...

3. En cuanto a su objeto material, el campo de los estudios de comunicación nunca se llega a definir por criterios teóricos sólidamente fundamentados (p.ej.: Peters, 1986; 1988), sino que queda establecido por acumulación de entes enormemente heterogéneos, entre los que, junto a las personas, están los sistemas informáticos, los transportes, los medios de comunicación, las redes sociales, las especies animales y vegetales, las neuronas, los genes, los elementos del sistema inmune, etc.

4. En cuanto a su objeto formal, tampoco existe un enfoque predominante claro, sino una confluencia de perspectivas diversas y hasta divergentes. Aunque un fenómeno tan complejo y poliédrico como la comunicación justifica la necesidad de la pluridisciplinariedad, con frecuencia se confunde esta con la mera yuxtaposición de puntos de vista, no solo carentes de un criterio rector integrador, sino incluso incompatibles.

5. Como consecuencia del énfasis en lo semejante, se difuminan o borran límites y diferencias que siempre habían estado claras para el sentido común; por ejemplo, las fronteras entre comunicación y mera percepción; entre acciones comunicativas humanas y relaciones no humanas; entre actos comunicativos intencionales y otros de carácter involuntario o 
inconsciente; entre actos comunicativos logrados y aquellos que resultan fallidos, etc.

La mera lectura de la enumeración anterior basta para percatarse de que el formalismo al que me vengo refiriendo resulta indeslindable de una gruesa falta de rigor, que procede, en buena parte, de él. Es claro que ambos asuntos - formalismo y carencia de rigor- no van necesariamente unidos. Pensemos, por ejemplo, en la ciencia matemática: sus axiomas y corolarios son abstracciones cuantitativas, cuya validez es independiente de sus referentes reales concretos (por ejemplo, $2+2=4$ es válido al margen de cuáles sean los seres reales con cuya cantidad estamos operando). Algo similar se puede decir de la Física (cuando estudiamos el movimiento de los cuerpos, no necesitamos conocer las características singulares de cada uno de ellos); o de la Lógica formal (que estudia la validez de los razonamientos, al margen de cuáles puedan ser sus referentes particulares).

Ahora bien, ¿ocurre lo mismo con la comunicación humana? ¿Tiene sentido un estudio formal de ella que prescinda del contenido y de las peculiaridades de los sujetos involucrados en el acto de comunicación? Aunque exigiría algunos matices, creo que la respuesta ha de ser negativa. $\mathrm{Si}$, para estudiar qué es comunicar, prescindimos de lo comunicado (al reducirlo a sus aspectos meramente formales), entonces difícilmente podremos llegar a entender cuál es la naturaleza de la acción comunicativa, porque habremos desechado su sustancia misma. En consecuencia, despreocuparse formalistamente del contenido de la comunicación (así como de lo que "ocurre" a emisor y destinatario al compartir ese contenido), implica cerrar el camino a entender qué es realmente aquello de lo que estamos hablando.

Creo que no es temerario aventurar que, desde sus orígenes, el campo de los estudios sobre comunicación ha estado severamente lastrado por serias faltas de rigor - derivadas en parte de un formalismo inadecuado a su objeto-, que han dificultado enormemente su consolidación y progreso. Más aún, en ocasiones, la divergencia de criterios y la escasez de rigor en el planteamiento de los temas de investigación han conducido - por decirlo parafraseando la conocida expresión de Feyerabend- a una especie de "anarquismo epistemológico", que explica, por ejemplo, la enorme proliferación de investigaciones de notable validez empírica, pero de poca 
valía teórica y de escasa relevancia ${ }^{11}$. A continuación, permítaseme ilustrar brevemente esta tesis, que considero crucial, desde la perspectiva del empleo de la metáfora.

\subsection{Sobre la laxitud conceptual derivada del uso de la metáfora}

Con su habitual perspicacia, John Durham Peters observa que el término "comunicación"

"sufre la desgracia de la confusión conceptual. Confusión, si se sugiere la mezcla de contornos intelectuales bien definidos, puede ser incluso un término demasiado preciso, puesto que "comunicación” existe en buena parte del discurso contemporáneo como una especie de plasma germinal malformado e indiferenciado" (Peters, 2000: 6).

En efecto, sin necesidad de detenerse ahora a considerar la pluralidad de acepciones diversas del término ${ }^{12}$, es patente que su uso indiscriminado genera confusión, dado que designa realidades completamente diversas como: el acto de tomar parte o compartir (uno de los sentidos originarios del vocablo latino original comunicare); el transporte o la transmisión de realidades físicas como el calor, la luz o la energía; el intercambio de significado a través de signos (con frecuencia llamado "interacción simbólica”); la expresión unidireccional de sentimientos con fines terapéuticos (como ocurre en el ámbito de la psiquiatría); la transferencia de materiales biológicos entre células; las conexiones del sistema nervioso; la variopinta diversidad de medios e instrumentos técnicos que permiten el contacto entre personas (desde el telégrafo, las banderas o las monedas, hasta la televisión, el cine o Internet); etc.

Pienso que esta enorme heterogeneidad de significados arranca del uso - a mi juicio- completamente laxo y desproporcionado que Shannon

${ }^{11}$ A este respecto, Wolfgang Donsbach observaba hace unos años, en un clarividente análisis acerca de la situación del campo, que en la actualidad este camina en la dirección de "demasiado procesamiento estadístico de poca importancia ['too much little number crunching'] y demasiado poco importantes cuestiones de investigación, es decir, investigación con tecnología de vanguardia y con validez, pero con poca relevancia y significación" (Donsbach, 2006: 447; cfr. también especialmente 444-446).

${ }^{12}$ Cfr. al respecto el capítulo The Problem of Communication, una muy lúcida y pormenorizada exposición sobre los distintos sentidos que se han dado históricamente al término "comunicación”, así como de las varias tradiciones y escuelas ligadas a ellos (Peters, 2000: 1-31).

Mediaciones Sociales, № 11, II semestre 2012, pp. 3-26. ISSN electrónico: 1989-0494. http://dx.doi.org/10.5209/rev_MESO.2012.v11.41267 
y Weaver hacen del término "comunicación” en 1949. Ya desde el principio de su célebre obra The Mathematical Theory of Communication, estos autores dejan claro que toman este vocablo en "un sentido muy amplio para incluir todos los procedimientos por los que una mente puede afectar a otra" (Shannon y Weaver, 1949: 95; mi cursiva). Y, por si hubiera margen para la duda, continúan:

"Este [sentido] incluye, por supuesto, no solo el discurso escrito y oral, sino también la música, las artes pictóricas, el teatro, el ballet, y de hecho toda conducta humana. Para algunas conexiones, puede ser deseable usar una definición de comunicación todavía más amplia; es decir, una que incluya los procedimientos por medio de los cuales un mecanismo (digamos un equipo automático que rastrea a un avión y calcula sus probables posiciones siguientes) afecta a otro mecanismo (digamos un misil guiado que persigue a este avión)" (Shannon y Weaver, 1949: 1; mi cursiva) ${ }^{13}$.

Dado que lo que buscan estos autores es lograr la máxima eficacia de las líneas telefónicas de la época, juzgo excesivo e injustificado que llamen "comunicación” a lo que solo es mera transmisión o transferencia de señales electrónicas. Igualmente, me parece arbitrario y desproporcionado que extrapolen el alcance de su teoría matemática al ámbito de la comunicación humana, para sentar las bases teóricas sobre esta, a partir de aquella. Para ellos, el discurso oral es equiparable a la transmisión de señales. De hecho, llegan a hacer explícita la comparación metafórica entre ambos cuando afirman: "en el discurso oral, la fuente de información es el cerebro, el transmisor es el mecanismo vocal que produce la presión sonora variable (la señal) que es transmitida a través del aire (el canal)" (Shannon y Weaver, 1949: 95; mi cursiva).

Me parece claro que, lo que podría aceptarse como metáfora, resulta excesivo y falaz, si se toma en sentido literal: el cerebro humano difícilmente puede ser reducido a un artefacto técnico; como tampoco puede ser reducida la acción humana libre a un proceso mecánico, ni los contenidos mentales a simple información entrópica, susceptible de ser codificada como señal. Por la misma razón, entender la comunicación humana en términos de transmisión de señales (incluso con significado) es simplificar

${ }^{13}$ Hago mío el comentario incisivo e irónico de Peters, cuando escribe: "extraordinaria categoría esta [la de comunicación], que incluye música y misiles, discursos y servomecanismos" (Peters, 2000: 25).

Mediaciones Sociales, № 11, II semestre 2012, pp. 3-26. ISSN electrónico: 1989-0494. http://dx.doi.org/10.5209/rev_MESO.2012.v11.41267 
la cuestión en demasía, hasta desvirtuar completamente el sentido y la adecuación de la comparación metafórica.

Curiosamente, los excesos metafóricos de la teoría matemática, lejos de producir rechazo, resultaron atractivos y valiosos para académicos de campos muy diversos, a lo largo de la década de 1950 (Peters, 2000: 25), lo que explica la gran eclosión del concepto de comunicación y la desproporcionada laxitud con la que se empezó a usar por doquier el término correspondiente ${ }^{14}$. A modo de mínima ilustración, citaré a continuación solo cuatro breves muestras. Comunicación es: (1) "el proceso por el cual un individuo (el comunicador) transmite estímulos (normalmente símbolos verbales) para modificar la conducta de otros individuos (comunicatarios)" (Hovland, 1948: 371; cit. por Nilsen, 1957: 11); (2) "la respuesta discriminatoria a un estímulo por parte de un organismo" (Stevens, 1950: 689); (3) "el proceso que conecta entre sí partes discontinuas del mundo vivo" (Ruesch, en Thayer, 1957: 462); y (4) "el proceso que pone en común a dos o varios lo que era el monopolio de uno" (Gode, 1959: 5).

Este mismo fenómeno empieza también a acaecer en los orígenes mismos de los Communication Studies. De nuevo, como ilustración, citaré solo a un autor: Wilbur Schramm, uno de los "padres fundadores" de la disciplina, que no tiene el menor empacho en intentar formalizar el objeto del nuevo dominio académico yuxtaponiendo, con perspicacia digna de mejor causa, realidades muy heterogéneas.

"En los Estados Unidos, la investigación sobre comunicación [escribe] se ocupa de todos los modos en que la información y las ideas son intercambiadas y compartidas. Así pues, estamos hablando tanto de la comunicación de masas como de la interpersonal. Hablamos de la palabra hablada, la señal, el gesto, la fotografía, la presentación visual, la imprenta, la radio, el cine - todos los signos y símbolos mediante los cuales los humanos tratan de transmitirse significado y valor unos a otros" (Schramm, 1963: 6).

Más adelante, al referirse a las relaciones interpersonales, continúa Schramm (1963: 6): “(...) hacer el amor, pedir prestada una taza de azúcar, decir "Buenos días", jugar un juego, cuidar que los niños del vecino no le

${ }^{14}$ Dance y Larson enumeran nada menos que 126 definiciones de comunicación (1976, apéndice A).

Mediaciones Sociales, № 11, II semestre 2012, pp. 3-26. ISSN electrónico: 1989-0494. http://dx.doi.org/10.5209/rev_MESO.2012.v11.41267 
pisen a uno las flores". Y, por si todavía quedara duda al perplejo lector, a modo de conclusión, afirma:

"La investigación sobre comunicación se ocupa, pues, de cómo ser eficaz en la comunicación, cómo ser entendido, cómo ser claro, cómo usa la gente los medios de comunicación, cómo las naciones pueden entenderse unas a otras, cómo puede la sociedad usar los medios de comunicación para su máximo provecho, y en general cómo funciona el proceso básico de la comunicación" (Schramm, 1963: 15).

\subsection{Sobre el pancomunicacionismo como abuso de la metáfora}

Una consecuencia estrechamente ligada a esta laxitud conceptual derivada de los abusos metafóricos a los que me vengo refiriendo, fue la instauración de una peculiar visión de los problemas relativos a la comunicación humana: el "pancomunicacionismo"15. Si lo que define a algo como objeto de comunicación es - con independencia de su contenido y efectos- la posibilidad de encuadrarlo en un proceso como el que describe la teoría matemática, entonces casi todo puede considerarse comunicación. Recordemos que, como hemos visto más arriba, Shannon y Weaver incluyen en dicho concepto nada menos que algo tan amplio como "toda conducta humana” (e incluso las interacciones entre sistemas automáticos).

Uno de los hitos más claros e influyentes del fenómeno pancomunicacionista tuvo lugar unos años después de la publicación de la teoría matemática: en 1967, el psicólogo Paul Watzlawick publicó, junto otros dos colegas, Don Jackson y Janet Beavin, un libro titulado Pragmatics of $\mathrm{Hu}$ man Communication (basado en parte en las ideas de George Bateson), que llegó a ser considerado, con el tiempo, una de las obras clásicas de teoría de la comunicación. En él se establece como “axioma” (así lo llaman) la idea de que "uno no puede no comunicar" (Watzlawick, Bavelas y Jackson, 1967: 48ss); es decir, que cualquier comportamiento humano - del tipo que sea- es necesariamente comunicativo (nótese que esta afirmación ya estaba presente, literalmente, en el texto de Shannon y Weaver antes citado). Desde entonces, esta tesis ha sido aceptada por buena parte de la comunidad académica y, con el tiempo, se ha divulgado ampliamente, hasta

${ }^{15}$ El término "pancomunicacionismo" no existe en el Diccionario de la Real Academia. Es acuñación mía.

Mediaciones Sociales, № 11, II semestre 2012, pp. 3-26. ISSN electrónico: 1989-0494. http://dx.doi.org/10.5209/rev_MESO.2012.v11.41267 
llegar a formar parte del acervo cultural popular, como si efectivamente se tratara de un axioma incuestionable.

Aunque no es este el lugar idóneo para revisar críticamente esta piedra angular del pancomunicacionismo ${ }^{16}$, puede ser conveniente, sin embargo, hacer unas rápidas observaciones al respecto.

1. Si se acepta como verdad incuestionable que toda conducta es, por definición, comunicativa, entonces quedan eliminadas las diferencias entre actos humanos intencionales y aquellos que no lo son: tan comunicativo sería afirmar algo consciente y deliberadamente como estornudar, hablar en sueños o incluso delirar. Sin embargo, es tan grande la distancia que separa las acciones humanas libres de aquellas involuntarias que el sentido común nos debería impedir considerar a ambas como pertenecientes a la misma categoría.

2. El argumento para considerar como comunicación también a los actos no intencionales es que todos ellos nos "transmiten" cierto significado. Según esto, la conducta animal o incluso la actividad de seres inanimados serían también comunicativas (porque "comunican” algún significado sobre el mundo) (Andersen, 1990). Ahora bien, si lo característico de la comunicación es la captación o recepción de significado, entonces se torna imposible distinguir entre percepción sensorial ${ }^{17}$, conocimiento intelectual y comunicación (la misma distinción carecería de sentido).

3. En línea con lo anterior, si confundimos percepción con comunicación, entonces la realidad deviene comunicativa: la mera existencia es comunicación. Y si todo es comunicación, entonces el significado del término se diluye por completo, para no significar nada. Dicho de otro modo: si

${ }^{16}$ Hay abundantes trabajos en esta línea. Singularmente, los de Michael Motley (1990a), cuya visión general del problema comparto. Es también muy enriquecedor el debate que mantiene este autor con Beach, Bavelas (Motley 1990b) y Andersen (Motley, 1991).

${ }^{17}$ Esto no significa, en modo alguno, que la percepción sea irrelevante para el éxito de la comunicación. Para empezar, porque sin percepción del otro como interlocutor, la comunicación carece de sentido y se frustra. Ahora bien, lo que es condición necesaria (como la conciencia del otro) no puede tomarse como condición suficiente, es decir, no basta para que se dé comunicación. Algo similar cabe decir de otros muchos asuntos que son relevantes para entender el acto comunicativo, sin por eso llegar a formar parte de él (por ejemplo, los medios técnicos empleados).

Mediaciones Sociales, № 11, II semestre 2012, pp. 3-26. ISSN electrónico: 1989-0494. http://dx.doi.org/10.5209/rev_MESO.2012.v11.41267 
algo es todo, entonces no es nada: los límites de su identidad desaparecen y acabamos por no saber de qué estamos hablando.

A la vista de estos argumentos (y de otros que ahora no podemos ni tan siquiera enunciar), si contemplamos esta cuestión desde la perspectiva aquí adoptada, no es aventurado afirmar que el pancomunicacionismo hace un abuso continuado de la metáfora, que resulta nocivo.

En efecto, en muchos de los ejemplos usados para argumentar a favor del supuesto axioma de Watzlawick, late el juego desproporcionado con las metáforas, cuyo sentido figurado acaba por volverse indeslindable del sentido literal. Así, quienes sostienen que la comunicación es independiente de la intencionalidad y que toda conducta es comunicativa, argumentan con ejemplos metafóricos presentados, de manera quizá inconsciente, como si el sentido figurado fuera literal. Solo así se puede entender que haya autores que afirmen seriamente que el ronroneo de un gato, el crujido de un árbol azotado por el viento o el aventar las moscas con el rabo de un caballo son comunicativos o formas de comunicación, equiparables en el fondo a las acciones comunicativas intencionales ${ }^{18}$. Y, por si algún lector juzga que tales ejemplos son forzados o gratuitamente extremos, baste con pensar en otra suerte de ejemplos similares, que han hecho fortuna y se han integrado plenamente en la cultura popular: me refiero a las frecuentes metáforas antropomórficas englobadas comúnmente bajo el rótulo de "lenguaje corporal" 19.

¿Cómo es posible llegar a negar las diferencias evidentes e insalvables entre la comunicación humana intencional y otro tipo de relaciones entre seres diversos que, aun poseyendo significado, no son equiparables a una

${ }_{18}$ Motley (1991: 333) cita estos ejemplos para criticar la posición de Andersen.

19 Pongamos un ejemplo para mostrar mejor lo absurdo de este planteamiento. La percepción del sentimiento de vergüenza, bochorno o incomodo que, con frecuencia, se manifiesta a través del rubor facial o sonrojo es, sin duda, relevante para la comunicación entre dos personas, en la medida en que permite que una de ellas perciba el estado emocional de la otra. Ahora bien, solo de manera metafórica e impropia, puede llamarse comunicativa a la acción de sonrojarse, porque, si bien es cierto que revela un estado de ánimo interior, lo hace en la mayoría de los casos contra la voluntad del afectado. Por mucho que se hable de "lenguaje corporal", lo último que suele querer alguien embargado por la vergüenza es que su cuerpo exprese o comunique ese sentimiento. En definitiva, si a una acción voluntaria de la persona le atribuimos el mismo valor comunicativo que a una involuntaria de su cuerpo, entonces no hay manera explicar la contradicción que existe entre decir algo voluntariamente y ser desmentido por el propio cuerpo.

Mediaciones Sociales, № 11, II semestre 2012, pp. 3-26. ISSN electrónico: 1989-0494. http://dx.doi.org/10.5209/rev_MESO.2012.v11.41267 
acción inteligente y libre? ¿Cómo se puede reparar tanto en las semejanzas entre seres radicalmente heterogéneos, como para llegar a equipararlos, a pesar de sus obvias diferencias?

Obviamente, preguntas de este tipo no pueden tener una respuesta satisfactoria, fruto de la demostración empírica o lógica. Quizá solo admitan hipótesis más o menos plausibles; por ejemplo, la aquí propuesta sobre el abuso de la metáfora. Así, cabe preguntarse: ¿no será que empieza uno por afirmar metafóricamente que "el Sol, al salir por la mañana, comunica su presencia”, para acabar por tomar la personificación al pie de la letra? ¿Acaso cuando atribuimos sentimientos y actitudes humanos a un animal, a una planta, o incluso a nuestro ordenador, no nos estaremos arriesgando a enredarnos en juegos de lenguaje que acaban por hacernos creer, contra toda evidencia, nuestras propias metáforas antropomórficas? Sean estas u otras las razones que explican la acusada tendencia contemporánea a abusar del lenguaje figurado, lo cierto es que resulta perjudicial — creo- para nuestra capacidad de entender el mundo, en la medida en que hace más arduo pensar las semejanzas y las diferencias de lo real.

\section{UNA REFLEXIÓN CONCLUSIVA}

Llegado el momento de poner punto final a este texto, quizá sea oportuno hacer una rápida valoración general más explícita acerca de la cuestión expuesta, a modo de reflexión conclusiva.

He empezado afirmando en la Introducción que la metáfora es un fecundo medio de desarrollar el pensamiento humano y un modo muy eficaz para su expresión, a condición de que respete la analogía entre el referente y su representación figurada. Ahora bien, dado que siempre es posible encontrar semejanzas entre los seres (aunque sea, como mínimo, su condición de "existentes"), invariablemente se corre el riesgo de desbordar los límites razonables de la analogía, comparando realidades en las que las diferencias son radical y desproporcionadamente mayores que las semejanzas. Cuando esto sucede, se comete abuso de la metáfora y esta se vuelve contraproducente: en lugar de iluminar el objeto metaforizado, acaba por simplificarlo o distorsionarlo hasta hacerlo irreconocible a nuestra mente. 
Como en otros ámbitos académicos, en el de los Communication Studies las metáforas campan por doquier y no siempre son usadas con sentido común y ponderación. Con frecuencia, se incurre en abuso, lo cual tiene consecuencias perjudiciales para la reflexión académica y, en definitiva, para el avance del conocimiento. Como he tratado de argumentar en las páginas precedentes, los problemas de definición conceptual que todavía aquejan al campo proceden, en una parte nada desdeñable, del abuso de una metáfora: la que proviene de la llamada "teoría matemática de la comunicación”. En efecto, la metáfora tecnológica subyacente en sus premisas básicas ha lastrado de formalismo y de falta de rigor buena parte de la reflexión sobre la comunicación humana. Esto ha producido y sigue produciendo, con frecuencia, situaciones cercanas al anarquismo epistemológi$\mathrm{co}^{20}$, de consecuencias indeseables.

Es verdad que no es demasiado raro encontrar partidarios de la situación de indefinición y laxitud conceptual que he criticado aquí. Son quienes ven en ella, más que una deficiencia, una oportunidad; por ejemplo, quienes piensan que, cuanta mayor es la indefinición de un concepto, mayor es su riqueza. O quienes celebran la "flexibilidad" y "apertura mental" que confiere adoptar un concepto vago o equívoco, cuya elasticidad tiende a infinito. Peters expresa esta idea con toda claridad y contundencia:

"A veces hoy la vacuidad de términos como comunicación se celebra como un bien, en lugar de considerarla un mal. Algunos dicen que el término no necesita ninguna especificación, porque es lo que uno quiera que sea. Pero tal visión solo continua el reinado de la legitimación institucional [o sea, de los intereses creados] sobre el vigor teórico. (...) No existen criterios teóricos para definir el campo. Y puesto que el único principio de organización conceptual que realmente funciona en este campo es el administrativo, cada departamento adopta sus propias definiciones, en función de sus peculiares características históricas y curriculares" (Peters, 1986: 547).

${ }^{20}$ Son muchas las muestras de este cuasi-anarquismo epistemológico. Mencionaré solo una de ellas, que no es peculiar de España: basta con consultar someramente una base de datos de tesis doctorales defendidas en nuestro país (como Teseo, por ejemplo), para percatarse de que, en las últimas décadas, se han presentado en las Facultades de Comunicación (o de nombre equivalente) disertaciones sobre los temas más variopintos, entre los que resultaría muy difícil, con frecuencia, establecer un mínimo de fundamentos comunes. Así las cosas, no sería extraño - digo a veces en broma- que un día se intentara defender una tesis que versara sobre "los vanos murales (ventanas) como medio de comunicación".

Mediaciones Sociales, № 11, II semestre 2012, pp. 3-26. ISSN electrónico: 1989-0494. http://dx.doi.org/10.5209/rev_MESO.2012.v11.41267 
En efecto, un cómodo expediente para esquivar la siempre peliaguda cuestión de definir un concepto es recurrir a formulaciones "abiertas" del tipo "sociología es lo que hacen los sociólogos" (Moya, 1970: 3). Es palmario que pseudo-descripciones tautológicas como esta conceden enorme "libertad" para decidir cuáles son los objetos de estudio y los modos de abordarlos y que, al hacerlo, tienen la ventaja de ser máximamente "inclusivas". Ahora bien, no es menos claro que esto no pasa de ser un mero subterfugio arbitrario, de muy corto alcance, que incurre en petición de principio, al plantear implícitamente la pregunta por el criterio que sirve para acreditar la condición de sociólogo (lo cual nos deja en la ignorancia inicial). Si "definir" significa "acotar", "establecer límites", es evidente que la laxitud conceptual, la falta de rigor o la arbitrariedad no son el mejor modo de acometer la siempre difícil tarea de sentar los fundamentos de una ciencia o rama del saber.

Pienso que, en el campo de los Communication Studies, las descripciones arbitrarias y omniabarcantes han prevalecido históricamente sobre los intentos rigurosos de definición en buena medida a causa del abuso de la metáfora. Aunque no me parece que esta hipótesis pueda probarse de manera empíricamente concluyente, la he aventurado aquí con la esperanza de que pueda servirnos de llamada a la reflexión. Quizá estemos todavía a tiempo de aprender de los errores del pasado y así contrarrestar la tendencia dominante a abusar de la metáfora, que tanto favorece el pensamiento débil contemporáneo, lastrado por el relativismo. Esto exige, obviamente, un notable esfuerzo común para ser extremadamente cuidadosos en la elección de las metáforas y para someter a análisis crítico las que circulan libremente en el discurso académico de nuestros días.

\section{Agradecimientos}

Quiero dejar aquí constancia de mi gratitud a mis colegas los profs. Dader y Núñez Ladevéze, que, mediante sus valiosos comentarios y observaciones, me han ayudado a mejorar el texto original. También agradezco muy de veras el trabajo de dos revisores anónimos, por sus positivos comentarios y útiles sugerencias, así como el apoyo del editor de la revista, prof. Baca Lagos, cuya eficiencia solo es excedida por su comprensión y amabilidad. 


\section{Bibliografía}

Andersen, P. A. (1990): "When one cannot not communicate: A challenge to Motley's traditional communication postulates", Communication Studies, 42, 4, pp. 309-325.

Dance, F. Y LaRson, C. (1976): The Functions of Human Communication: A Theoretical Approach. New York : Holt, Rinehart \& Winston, apéndice A.

Donsbach, W. (2006), "The Identity of Communication Research", Journal of Communication, 56, pp. 437-448.

GleICK, J. (2011): The Information: a History, a Theory, a Flood. New York: Pantheon Books (ed. esp.: trad. de J. Rabasseda y T. de Lozoya (2012): La información. Historia y realidad. Barcelona: Crítica).

GODE, A. (1959): "What is communication", Journal of Communication, 9, pp. 3-20.

Hovland, C. (1948): "Social Communication", Proceedings of the American Philosophical Society, XCII; cit. por NILSEN, T. (1957): "On Defining Communication", The Speech Teacher, vol. 6, 1, pp. 10-17.

Lakoff, G. y Johnson, M. (1980a): "Conceptual Metaphor in Everyday Language", The Journal of Philosophy, vol. 77, 8, pp. 453-486.

Lakoff, G. y Johnson, M. (1980b): Metaphors We Live By. Chicago: University of Chicago Press. (Trad. esp. 2001: Metáforas de la vida cotidiana. Madrid: Cátedra).

JAKOBSON, R. (1960): "La lingüística y la poética", en Ensayos de lingüística general, Barcelona: Seix Barral, 1975, pp. 347-395 (ed. o.: "Closing Statements: Linguistics and Poetics", en SEBEOK, Thomas A., Style In Language, Cambridge Massachusetts: MIT Press, 1960, pp. 350-377).

JaKobSOn, R. y Halle, M. (1956): "The metaphoric and metonymic poles", en Fundamentals of Language, Mouton \& Co., The Hague, pp. 76-82.

MoyA, C. (1970): Sociólogos y Sociología. Madrid: Siglo XXI.

Motley, M. (1990a): "On Whether One Can(not) Not Communicate: An Examination via Traditional Communication Postulates", Western Journal of Speech Communication, 54, 1, pp. 1-20.

Mediaciones Sociales, № 11, II semestre 2012, pp. 3-26. ISSN electrónico: 1989-0494. http://dx.doi.org/10.5209/rev_MESO.2012.v11.41267 
Motley, M. (1990b): "Communication as Interaction: A Reply to Beach and Bavelas", Western Journal of Speech Communication, 54, 4, pp. 613-623.

Motley, M. (1991): "How One May Not Communicate: A Reply to Andersen", Communication Studies, 42, pp. 326-339.

Peters, J. D. (1986): "Institutional Sources of Intellectual Poverty in Communication Research", Communication Research, vol. 13, n. 4, pp. 527-559.

Peters, J. D. (1988): "The Need for Theoretical Foundations: Reply to Gonzalez", Communication Research, vol. 15, n. 3, pp. 309-317.

Peters, J. D. (2000): Speaking into the Air. A History of the Idea of Communication. Chicago: University of Chicago Press.

Ruesch, J. (1957): "Technology and Social Communication", en Thayer, L.: Communication Theory and Research. Springfield: Charles C. Thomas, pp. 452-81.

SCHRAMM, W. (1963): "Communication Research in the United States", en SCHRAMM, W. (ed.): The Science of Human Communication: New Directions and New Findings in Communication Research. New York: Basic Books, pp. 1-16.

Shannon, C. (1948): "A Mathematical Theory of Communication", The Bell System Technical Journal, vol. 27, 3, pp. 379-423.

Shannon, C. y Weaver, W. (1949): The Mathematical Theory of Communication. Urbana: University of Illinois Press.

Stevens, S. (1950): "Introduction: A Definition of Communication", The Journal of the Acoustical Society of America, XXII, pp. 689-690.

Watzlawick, P., Bavelas, J. B. y Jackson D. D. (1967): Pragmatics of Human Communication: A Study of Interactional Patterns, Pathologies, and Paradoxes. New York: W. W. Norton \& Co.. 


\section{PARA CITAR ESTE TRABAJO EN BIBLIOGRAFÍAS:}

MUÑOZ-TORRES, Juan Ramón (2012): “Abuso de la metáfora y laxitud conceptual en comunicación”, Mediaciones Sociales. Revista de Ciencias Sociales y de la Comunicación, $\mathrm{n}^{\circ} 11$, pp. 3-26.

DOI: http://dx.doi.org/10.5209/rev_MESO.2012.v11.41267

\section{${ }^{(*)}$ El autor}

Juan Ramón Muñoz-Torres es profesor Titular de Periodismo en la Facultad de Ciencias de la Información de la Universidad Complutense de Madrid, a cuyo claustro docente pertenece desde 1990. Es licenciado, con Premio Extraordinario, en Ciencias de la Información por la Universidad de Navarra (1986) y Doctor por la Universidad Complutense de Madrid (1989). Gracias a una beca Fulbright concedida en 1989, fue Visiting $\mathrm{Fe}$ llow en el Departamento de Filosofía de la Universidad de Harvard (198990), donde desarrolló investigación bajo la dirección del profesor Hilary Putnam. Ha sido profesor de Epistemología de la Comunicación en la citada Facultad. En la actualidad imparte asignaturas de construcción textual y argumentación retórica. Es autor de 2 monografías y de más de 20 artículos (varios de ellos en revistas anglosajonas). Su investigación actual está centrada en el ámbito de la filosofía de la comunicación, con especial énfasis en asuntos relativos a la relación entre conocimiento, objetividad y verdad; narrativa y argumentación retórica; y responsabilidad social de los medios. Recientemente, ha sido nombrado miembro del consejo editorial de la prestigiosa revista Journalism Studies.

RECIBIDO: 28 de octubre de 2012.

ACEPTADO: 13 de diciembre de 2012. 